\title{
(t)
}

\section{ANOS DO MOVIMENTO ESTUDANTIL DE SERVIÇO SOCIAL: DESAFIOS E PERSPECTIVAS NA ATUALIDADE}

\author{
4OYEAR OF THE SOCIAL SERVICE STUDENT MOVEMENT: CURRENT CHALLENGES AND \\ PERSPECTIVES
}

\author{
Isabelle Cristina Custódio de Lima* \\ https://orcid.org/0000-0001-6877-596X
}

\begin{abstract}
RESUMO
O presente ensaio, aborda a trajetória histórico-política dos 40 anos do Movimento Estudantil de Serviço Social (MESS) e 30 anos da Executiva Nacional de Estudantes de Serviço Social (ENESSO), focando nos desafios contemporâneo da sua organização política, com recorte na Região II. Resulta de sucessivas aproximações com a totalidade social, fruto da nossa trajetória e experiência no movimento, à luz do método materialista histórico-dialético, constituindo objeto de análise crítica por meio de revisão de literatura e pesquisa documental. As análises tecidas permitem afirmar que diversos desafios são recorrentes e constantes ao longo dos anos, principalmente a partir do advento dos ideais neoliberais. Contudo, nenhum desafio (im)posto ao MESS/ENESSO, pode ser compreendido de forma isolada do seu tempo histórico. Neste sentido, é preciso apostar nas contradições que surgem de todo processo determinado pela luta de classes, e utilizar-se da nossa inteligência e aptidão de mobilização para produzir, em conjunto com sujeitos coletivos e individuais, estratégias com potencial de enfrentar esse processo.
\end{abstract}

\section{PALAVRAS-CHAVE}

Movimento Estudantil de Serviço Social. Região II. Desafios.

\begin{abstract}
This essay discusses the historical-political trajectory of the 40 years of the Social Service Student Movement (MESS) and 30 years of the National Executive of Social Service Students (ENESSO), focusing on the contemporary challenges of its political organization, with Crop in Region II. It is Apparent from successive approximations with the social totality, the fruit of our trajectory and experience in the movement, in the light of the historical-dialectical materialist method, constituting the object of critical analysis through literature review and documentary research. The woven analyses allow us to affirm that several challenges are recurrent and constant over the years, mainly from the advent of neoliberal ideals. However, no challenge (im)posed to MESS/ENESSO can be understood in isolation from its historical time. In This sense, it is necessary to bet on the contradictions that arise from every process determined by the class struggle, and use of our intelligence and mobilization aptitude to produce, together with collective and individual subjects, strategies with Potential to tackle this process.
\end{abstract}

\footnotetext{
* Bacharel em Serviço Social pela Faculdade Estácio do Rio Grande do Norte (2017). Residente Multiprofissional em Atenção Básica pela Escola Multicampi de Ciências Médicas de Caicó (RN). Especialista em Políticas Sociais Integradas pela Faculdade Estácio do Rio Grande do Norte. E-mail: <isabelle_c.d.l@hotmail.com>.
}

\section{DOI 10.22422/temporalis.2019v19n38p37-51}

(cc) Br Commons Atribuição 4.0 Internacional (https://creativecommons.org/licenses/by/4.o/deed.pt_BR), que permite copiar e redistribuir o material em qualquer suporte ou formato, bem como adaptar, transformar e criar a partir deste material para qualquer fim, mesmo que comercial. O licenciante não pode revogar estes direitos desde que você respeite os termos da licença.

Temporalis, Brasília (DF), ano 19, n. 38, p. 37-51, jul./dez. 2019. | ISSN 2238-1856 


\section{KEYWORDS}

Student Movement of Social Work. Region II. Challenges.

Submetido em: 1/4/2019.

Aceito em: 12/11/2019.

\section{INTRODUÇÃO}

Em 2018, o Movimento Estudantil de Serviço Social (MESS) comemorou os 40 anos de sua rearticulação e 30 anos de existência da Executiva Nacional de Estudantes de Serviço Social (ENESSO). Nesse contexto, a executiva se depara com um quadro de dificuldades no interior do movimento, expressas em um intenso período de desarticulações e de desmobilização, não somente, das suas bases, como também, em suas direções, em nível nacional mas, também (e com especificidades diversas), no âmbito das articulações regionais.

Este panorama segue a tendência das organizações políticas da esquerda brasileiras, as quais tem sofrido os rebatimentos do aprofundamento da crise do capital, que tem implicado diretamente sobre suas formas de organização e resistência. As transformações verificadas no modo de produção capitalista sob hegemonia do capital financeiro, têm repercutido no adensamento das diretivas neoliberais, na intensificação das privatizações dos serviços sociais públicos, na reestruturação produtiva, na precarização do trabalho, bem como, na dimensão ideocultural, com especial destaque para a disseminação do pensamento pós-moderno (SIMIONATTO, 2009). Todos esses acontecimentos rebatem diretamente na forma de viver, produzir e de pensar da classe trabalhadora e, consequentemente, na sua forma de organização política e nas formas de resistência que engendras.

Nesse contexto, muitos desafios político-organizativos são enfrentados pelo MESS/ENESSO, em suas múltiplas instâncias e dimensões. Diante disso, várias/os autoras/es se dedicaram a pesquisar os desafios e as possibilidades referentes às proposições, articulações, mobilizações, inserções e renovações de quadros dentro do MESS/ENESSO, bem como aos limites, dificuldades e desafios que se materializam para o segmento estudantil em apreço, contribuindo para o acúmulo histórico-político do MESS. Dentre esses/as autores/as podemos citar: Ramos (1996), Vasconcelos (2003), Guimarães (2011), Oliveira (2014), dentre outras/os, pesquisaram sobre a temática construindo um legado para o acúmulo teórico e histórico-político do MESS.

Partindo deste acúmulo e de um conjunto de inquietações que dinamizam a realidade contemporânea, o presente trabalho objetiva, resgatar os principais acontecimentos que marcaram a trajetória histórico-política dos 40 anos do MESS e dos 30 anos da ENESSO bem como, problematizar e elucidar, numa perspectiva crítica, alguns desafios do MESS no atual cenário de crise, em particular o da Região II da ENESSO. Buscando oferecer novos aportes teóricos para ampliar a produção teórica já existente na área e, consequentemente, avançar no esforço histórico de construção coletiva do MESS, reafirmando a necessidade da articulação e do fortalecimento desse movimento, para que esse seja um processo contínuo de reflexões, enriquecendo e tornando cada vez mais viva a práxis revolucionária. 
No percurso metodológico, foi utilizada a pesquisa do tipo exploratória, por meio de revisão de literatura e pesquisa documental. Além disso, este texto também sistematiza alguns dados fruto da nossa trajetória e experiência no movimento', à luz do método materialista histórico-dialético, afim de conseguir analisar a conjuntura de forma crítica e buscar trazer de forma mais dialética a realidade supracitada. Considera-se, portanto, que o objeto estudado, por seu caráter social e histórico, é dinâmico e multifacetado e jamais se esgotaria nesta análise temporal e espacial, visto que se relaciona diretamente com o movimento dos descaminhos produzidos pelas lutas de classe em nossa sociedade.

O artigo se divide em duas sessões: na primeira delas, buscamos, brevemente, discorrer acerca da história político-organizativa do MESS/ENESSO, centrando nos principais marcos históricos evidenciados ao longo dos 40 anos de sua rearticulação; na segunda sessão, tomamos para nós a tarefa de problematizar os desafios contemporâneos da organização política do MESS/ENESSO, com recorte na Região II.

\section{SUJEITOS HISTÓRICOS E PROTAGONISMO SOCIAL: 40 ANOS DA REARTICULAÇÃO DO MOVIMENTO ESTUDANTIL DE SERVIÇO SOCIAL}

O Movimento Estudantil (ME), constituiu-se historicamente como uma das formas de organização política da juventude, possui uma hegemônica direção social sintonizada com os interesses da classe trabalhadora, exercendo, por isso um papel relevante na construção das lutas sociais. Atuou ativa e decisivamente em vários momentos da história brasileira, a exemplo do processo de redemocratização do Brasil, no período de Ditadura Militar. Isso porque, apesar de construir uma agenda de lutas pautada na defesa de uma educação pública, gratuita, laica, de qualidade e socialmente referenciada, também projeta suas ações para um escopo de pautas que interessam a sociedade, de modo geral. Assim, não é casual que, nos dias atuais, o Movimento Estudantil seja um dos sujeitos coletivos, que atua no aprofundamen e na defesa da democracia.

Corroboramos com as concepções de Silva (2008) e Moreira (2016), segundo as quais o Movimento Estudantil se configura enquanto um Movimento Social, que aglutina a juventude, caracterizando-se como um dos sujeitos de ação coletiva de caráter contestador. Sendo indissociável das relações macrossocietárias, devendo ser pensado a partir das múltiplas determinações e contradições que abrangem sua totalidade social.

É imprescindível salientarmos que a história do Movimento Estudantil de Serviço Social (MESS), embora relacionada e construída a partir das peculiaridades inerentes do próprio curso, não acontece deslocada do contexto e das ações da histórica do ME geral, consequentemente da União Nacional de Estudantes (UNE), pois são processos imbricados, porém, interdependentes. Embora apontada esta premissa, importa ressaltar que, nos marcos desse artigo não será abordado sobre o processo histórico do ME geral, uma vez que, este não é o foco desta pesquisa.

Conforme Moreira (2016), os/as estudantes de Serviço Social possuem um papel fundamental no processo de organização política da categoria profissional. Entendidos

\footnotetext{
${ }^{1}$ Através da militância no Centro Acadêmico Ilena Felipe Barros da Estácio/FATERN - Gestões 2013/2014 Reconstruir e avançar e 2014/2015 Nenhum passo atrás -, e na Coordenação Regional da ENESSO - Gestão 2014/2015 A luta é direito de fazer um mundo novo.
}

Temporalis, Brasília (DF), ano 19, n. 38, p. 37-51, jul./dez. 2019. | ISSN 2238-1856 
enquanto profissionais em formação, participaram ativamente, através do MESS, da construção das bandeiras de luta erguidas pelo Serviço Social, - contribuindo para a reconfiguração da profissão no Brasil. Neste sentido, são sujeitos políticos que corroboram na defesa e reafirmação dos valores ético-político hegemônicos da categoria, colocando-se na contramão dos ideários concernentes ao projeto neoconservador e neoliberal, os quais ainda estão presentes e/ ou cada vez mais crescentes no corpo profissional.

No que se refere a história do MESS, de acordo com Santos (2007), foram localizados documentos históricos que apontam a existência de organização política das/os estudantes de Serviço Social, num período anterior ao ano de 1953. Todavia, pode-se considerar como um marco significativo a ocorrência do primeiro Encontro Nacional de Estudantes de Serviço Social, realizado na cidade de Porto Alegre (RS), em 1963, que resulta na fundação da Executiva Nacional dos Estudantes de Serviço Social (ENESS).

A ENESS teve sua atuação até meados de 1968, momento histórico no qual, sob os auspícios da ditadura autocrático-burguesa, estabelece-se o Ato Institucional número 5 $(\mathrm{Al}-5)^{2}$, impedindo todas as formas de organização coletiva e de expressão política existentes. Neste sentido, assim como as demais organizações políticas existentes à época, no período ditatorial, o MESS sofreu duras repressões, tendo seus registros históricos queimados e/ou extraviados, não podendo localizar registros da atuação política nesse período.

A partir do endurecimento e das medidas coercitivas do regime militar a ENESS, bem como a UNE, CA's, DA's e DCE's - entidades que compõem a estrutura do movimento estudantil - foram proibidas de exercerem suas atividades. Os registros dos encontros, bem como muitos documentos históricos da ENESS foram queimados e/ou extraviados pelo regime militar, sendo inexistentes nos arquivos da atual Executiva Nacional de Estudantes de Serviço Social - ENESSO. Vale ressaltar que no período de ditadura militar, muitos registros como atas, documentos e reuniões não foram feitos devido à repressão (SANTOS, 2007, p. 112-113).

O final da década de 1970 marca uma perspectiva de abertura política no Brasil, com importantes manifestações e greves, com destaque para a organização dos metalúrgicos no ABC Paulista e com a formação de um bloco de esquerda e classista que, em 1983, fundaria a Central Única dos Trabalhadores (CUT). Além disso tem-se a anistia parcial das/os exiladas/os, o fim do bipartidarismo, a extinção do $\mathrm{Al}$ - 5 e rearticulação do $\mathrm{ME}$ em âmbito nacional.

É nesse cenário, que o MESS volta a se rearticular, com a realização no ano de 1978, em Londrina (PR), o I Encontro Nacional das/os Estudantes de Serviço Social (ENESS) "pósditadura", reunindo cerca de 24 (vinte e quatro) escolas, tendo como tema 'O Serviço Social e a Realidade Brasileira'. A partir deste momento, os encontros passam a ocorrer

\footnotetext{
${ }^{2}$ Emitido em 13 de dezembro de 1968, foi o quinto decreto expedido pelo governo militar brasileiro. Sendo o mais duro golpe na democracia, onde dava poderes quase absolutos ao regime militar. Tinha como suas principais determinações: a proibição de manifestações populares de caráter político, impor a censura prévia a jornais, revistas, peças teatrais, músicas e livros...
}

Temporalis, Brasília (DF), ano 19, n. 38, p. 189-205, jul./dez. 2019. | ISSN 2238-1856 
anualmente e o MESS vai se moldando e fortalecendo sua estrutura organizativa (EXECUTIVA NACIONAL DE ESTUDANTES DE SERVIÇO SOCIAL, 1994).

O IV ENESS, sediado em Recife (PE), pela Universidade Federal do Pernambuco (UFPE), em 1981, foi marcado pela presença de profissionais e diversos partidos políticos, contribuindo no debate estudantil. E a nível de formação profissional, os debates propostos pelo MESS estavam sintonizados com o conjunto de discussões que se desenrolavam no corpo profissional e, por isso, evidenciava-se a necessidade de romper com o modelo tradicionalista e conservador da profissão e com a dicotomia teórica e prática. É nesse encontro ainda, que se garante a mudança na estrutura, dá Associação Brasileira de Ensino em Serviço Social (ABESS) - atual Associação de Ensino e Pesquisa em Serviço Social (ABEPSS) -, que contará com a participação de um/a estudante por região (EXECUTIVA NACIONAL DE ESTUDANTES DE SERVIÇO SOCIAL, 1994).

Após a manutenção dos debates acerca da forma de organização e representação do MESS, no X ENESS em 1988, no Rio de Janeiro/RJ, constitui-se como marco a criação da Subsecretaria de Estudantes de Serviço Social da UNE (SESSUNE), cuja finalidade era potencializar a organização política das/os estudantes de Serviço Social junto a UNE.

O processo de criação da entidade nacional dos(as) estudantes de Serviço Social foi, democraticamente, discutido e amadurecido em vários fóruns, pelos(as) próprios estudantes e pelas suas entidades de base, propiciando reflexões quanto à própria necessidade da sua criação e, um aprofundamento sobre quais seriam seus objetivos e sua estrutura organizativa (RAMOS, 1996, p. 102)

No XV ENESS, realizado em São Leopoldo/RS, em 1993, após um longo debate acerca da atuação da UNE, as/os estudantes deliberam a mudança de nomenclatura da entidade, deixando de ser SESSUNE para tornar-se Executiva Nacional de Estudantes de Serviço Social (ENESSO), com o intuito de garantir uma maior autonomia política com relação a UNE, bem como, no fortalecimento das lutas específicas do Serviço Social.

Guimarães (2011) salienta, que "[...] esta não foi uma alternativa isolada do Serviço Social, mas uma estratégia de organização política das/os estudantes das diversas áreas, que defendiam as executivas de curso como uma alternativa viável no processo de reorganização estudantil" (GUIMARÃES, 2011, p. 43). Ademais, não custa lembrar que, na década de 1990, um conjunto de determinações econômicas, sociais e políticas 3 passam a fazer parte da realidade, fazendo-se visível um processo de refluxo dos movimentos sociais e sindicais, que impactam, em maior ou menor medida, os rumos das lutas sociais, inclusive do Movimento Estudantil.

Sendo assim, a ENESSO torna-se a entidade máxima de representação das/os estudantes de Serviço Social no país, garantindo sua autonomia, estimulando, unificando e fortalecendo a luta das/os estudantes de Serviço Social, numa direção classista, anticapitalista e revolucionaria, aliada a um projeto societário sem dominação, exploração

\footnotetext{
${ }^{3}$ Do ponto de vista socioeconômico, a década de 1990 é marcado por elevadas taxas de inflação, baixo nível de investimento público e privado, problemas de endividamento, aumento da questão social e a implementação da política neoliberal, marcada pelo acervo das reformas orientadas para o mercado, tendo no reforço as privatizações e na mínima intervenção estatal o caminho para o novo projeto de modernidade. (BEHRING; BOSCHETTI, 2011).
}

Temporalis, Brasília (DF), ano 19, n. 38, p. 37-51, jul./dez. 2019. | ISSN 2238-1856 
de classe, gênero, sexualidade, raça e etnia (EXECUTIVA NACIONAL DE ESTUDANTES DE SERVIÇO SOCIAL, 2013).

A estrutura organizativa da ENESSO encontra-se definida no estatuto da entidade, tendo sua revisão prevista a cada três anos, e compreende-se, fundamentalmente, em: composição e atribuições da Diretoria, a instâncias organizativas e deliberativas e a divisão regional das escolas. Por seu caráter democrático e plural, o MESS confere espaços constantes para rediscussões da sua dinâmica político-organizativa, sendo passível de alterações, a depender da necessidade dos sujeitos que constroem cotidianamente o MESS e seus fóruns deliberativos

Para garantir uma melhor articulação entre as/os estudantes a nível nacional, a ENESSO possui uma Coordenação Nacional (CN), que é responsável por executar as estratégias e táticas deliberadas nos encontros nacionais. Conforme Guimarães (2011) a CN "[...] cumpre papel relevante para a organização do MESS, à medida em que direciona as ações e posicionamentos políticos da entidade em torno de determinado projeto ideológico" (GUIMARÃES, 2011, p. 45).

No percurso histórico da SESSUNE/ENESSO, a Executiva ficou sem gestão na CN em dois momentos: o primeiro na gestão 2008/09, em decorrência da falta de consenso entre os agrupamentos políticos que disputavam a gestão nacional da ENESSO, no XXX ENESS, realizado em Londrina (PR) (EXECUTIVA NACIONAL DE ESTUDANTES DE SERVIÇO SOCIAL, 2014); e o segundo, na gestão 2017/18, devido a não realização do XXXIX ENESS, que seria realizado em Salvador (BA), mas em virtude do baixo número de inscritos foi cancelado.

É importante sinalizar, que a ausência de gestão na CN dificulta, significativamente, a dinâmica político-organizativa do MESS, principalmente com relação à efetivação de lutas em âmbito nacional e a articulação com as demais entidades da categoria.

No quadro abaixo, podemos observar as gestões que construíram a SESSUNE/ENESSO no decorrer desses 30 anos:

Quadro 01 - GESTÕES NACIONAL DA SESSUNE/ENESSO 1988-2018

\begin{tabular}{|c|c|l|}
\hline $1988 / 89$ & $* * * * * * * * *$ & $\begin{array}{l}\text { Márcia Torres (UFRJ), Denise Costa (PUC-BH), Lúcia Barbosa } \\
\text { (UFF-Niterói) e Teresa Cristina (UFJF). }\end{array}$ \\
\hline $1989 / 90$ & $* * * * * * * * *$ & $\begin{array}{l}\text { Raimunda Ferreira (UECE), Verônica Gomes (UFPB), Mabel } \\
\text { Rodrigues (UFPB) e Alcinéia Souza (UECE). }\end{array}$ \\
\hline $1990 / 91$ & $\begin{array}{c}\text { O pulso ainda pulsa e } \\
\text { um militante ainda é } \\
\text { pouco }\end{array}$ & $\begin{array}{l}\text { Sâmia Ramos (UECE), Antoinete de Brito (UFRN), Fernanda Queiroz } \\
\text { (UECE) e André França (UFPE). }\end{array}$ \\
\hline $1991 / 92$ & $\begin{array}{c}\text { Quem é de luta não se } \\
\text { cansa }\end{array}$ & $\begin{array}{l}\text { Evandro Silva (UFPA), Pedro N. B. Júnior (UFPA), Claudionor Dias } \\
\text { (UFPA) e Maria G. Silva (UFPI.) }\end{array}$ \\
\hline $1992 / 93$ & $\begin{array}{c}\text { Pro dia nascer feliz } \\
\text { Ângela Madeiro (UECE), Sâmbara Ribeiro (UECE), Derleide Andrade } \\
\text { (UECE) e Rosângela Amorim (UNICAP). }\end{array}$ \\
\hline $1993 / 94$ & $\begin{array}{c}\text { Enquanto a chama } \\
\text { arder }\end{array}$ & $\begin{array}{l}\text { Maria Pimentel (UCSAL), Patrícia Vieira (UCSAL), Gabriela Guerreiro } \\
\text { (UCSAL), Liane Souza (UCSAL) e Luciana Alencar -Representantes } \\
\text { Estudantis em ABESS - (UECE). }\end{array}$ \\
\hline $1994 / 95$ & Nosso próprio tempo & $\begin{array}{l}\text { Marcelo Braz (UFRJ), Adriana Vasconcelos (UERJ), Elizabete Amorim } \\
\text { (UFJ), Maurílio Matos (UFRJ) e Luciana Alencar -Representante } \\
\text { Estudantis em ABESS - (UECE). }\end{array}$ \\
\hline
\end{tabular}

Temporalis, Brasília (DF), ano 19, n. 38, p. 189-205, jul./dez. 2019. | ISSN 2238-1856 


\begin{tabular}{|c|c|c|}
\hline $1995 / 96$ & Vamos nos permitir & $\begin{array}{l}\text { Cristina Nascimento (UECE), Alzira Nogueira (UECE), Fátima Souza } \\
\text { (UECE), Valdência Santos (UECE) e Sandra Mara - Representante } \\
\text { Estudantis em ABESS - (UECE). }\end{array}$ \\
\hline $1996 / 97$ & $\begin{array}{l}\text { Remando contra a } \\
\text { maré }\end{array}$ & $\begin{array}{l}\text { Emanuel Sabóia (UECE), Andréa Mesquita (UECE), Mirian Inácio } \\
\text { (UFRN), Dalvanir Avelino (UFRN) e Sandra Mara - Representante } \\
\text { Estudantis em ABESS -. (UECE) }\end{array}$ \\
\hline $1997 / 98$ & Um convite à rebeldia & $\begin{array}{l}\text { Davalnir Avelino (UFRN), Elizabete Cruz (UECE), Fátima Tomás } \\
\text { (UFRN), Mírla Cisne (UECE) e Tatiana Raulino (UECE). }\end{array}$ \\
\hline $1998 / 99$ & Nós queremos mais & $\begin{array}{l}\text { Charles Souza (UFRJ), Gabriele Bastos (UFF/Niterói), Loraine R. Vigo } \\
\text { (UERJ), Jaime Neto (UFRJ) e Wanusa Santos (UFES). }\end{array}$ \\
\hline $1999 / 00$ & $\begin{array}{l}\text { De norte a sul, } \\
\text { construindo muito } \\
\text { mais }\end{array}$ & $\begin{array}{l}\text { Daniela Vieira (UFMA), Maria Carvalho (UNAMA), Yara Felipe (UFPI), } \\
\text { Edson Silva (UFPA) e Andréia Ewerton (UFMA). }\end{array}$ \\
\hline $2000 / 01$ & $\begin{array}{l}\text { Compromisso e } \\
\text { resistência }\end{array}$ & $\begin{array}{l}\text { Tatiana Andrade (UFS), Maria da Conceição Souza (UFS), Aiane } \\
\text { Oliveira (UCSAL), Érica da Silva (UCSAL) e Karlene Sampaio (UFS). }\end{array}$ \\
\hline $2001 / 02$ & $\begin{array}{l}\text { Na luta pela } \\
\text { transformação não há } \\
\text { limites }\end{array}$ & $\begin{array}{l}\text { Juliana Cosac (UCG), Fernanda Fernandes (UNB), Gisele Silva (UCG), } \\
\text { Wellington Rodrigues (UNG), Leila Teixeira (UCG), Elivânia Lima } \\
\text { (UFMT) e Ludimila Levyski (UNB). }\end{array}$ \\
\hline $2002 / 03$ & $\begin{array}{l}\text { Na luta e na ação eu } \\
\text { quero é mais } \\
\text { transformação }\end{array}$ & $\begin{array}{l}\text { Joel Oliveira (UNIVALE), Kátia Custódio (UFES), Luciano Azevedo } \\
\text { (UFES), Ronan Costa (UNIPAC), Ana Paula Procópio (UERJ), Moara } \\
\text { Zanetti (UERJ) e Rafaela Binoti (UFF-Campos). }\end{array}$ \\
\hline $2003 / 04$ & $\begin{array}{l}\text { ENESSO na luta para } \\
\text { fazer sua própria } \\
\text { história }\end{array}$ & $\begin{array}{l}\text { Adriana Oliveira (PUC-SP), Wagner Hosokawa (PUC-SP), Lucilene } \\
\text { Gomes (PUC-Campinas), Graziela Sue (UNISAL), Michele Marx } \\
\text { (Barão de Mauá-SP), Julia Benedini (UNESP) e Anita Martins } \\
\text { (UNESP) }\end{array}$ \\
\hline $2004 / 05$ & Viver na luta & $\begin{array}{l}\text { Ana Caroline Trindade (UFS), Daniele Rebouças (UCSAL), Amanda } \\
\text { Bastos (UFS), Aline Araújo (UCSAL), Jackeline Mirne (UNIT), } \\
\text { Itanamara Cavalcante (UFS) e Fernanda Mantelli (UCSAL). }\end{array}$ \\
\hline $2005 / 06$ & A luta não pode parar & $\begin{array}{l}\text { Celso Severo Silva (UFPE), Nathália Teixeira (UFPE), Juliana Nunes } \\
\text { (UFPB), Evandro Correia Junior (UFPB), Albertina Felix (UEPB), } \\
\text { Raquel Mazule (UERN) e Alison de Araújo (UEPB). }\end{array}$ \\
\hline $2006 / 07$ & Todos/as na luta!!! & $\begin{array}{l}\text { Fabiano Santos (UFAL), Roberto Alves (UCSAL), Emanuela Brito } \\
\text { (UCSAL), Aline Cerqueira (UCSAL), Daisy Morais (UCSAL), Aline } \\
\text { Tapioca (UCSAL) e André Dória (UFS). }\end{array}$ \\
\hline $2007 / 08$ & $\begin{array}{l}\text { OUSAR E UNIR: } \\
\text { 'todos/as juntos/as } \\
\text { para construir' }\end{array}$ & $\begin{array}{l}\text { Shanti Mairananda de Oliveira (UFJF), Samantha Santos (PUC-BH), } \\
\text { Aline Barreto (UFES), Ernandes José (UFVJM), Leonardo Reis (PUC- } \\
\text { BH), Haimon Verly (UFES) e Cristóvão Braga (UFJF) }\end{array}$ \\
\hline $2008 / 09$ & $\begin{array}{l}\text { NÃO HOUVE } \\
\text { COORDENAÇÃO } \\
\text { NACIONAL }\end{array}$ & $* * * * * * * * * * *$ \\
\hline $2009 / 10$ & Nada será como antes & $\begin{array}{l}\text { Clara Saraiva (UFRJ), Letícia Masuet (UERJ), Luciana Freitas (UFRJ), } \\
\text { Rosy Hellen (UFF-Niterói), } \\
\text { Malú Vale (UFRJ), Rafaela Albergaria (UFRJ) e Eder Frossard } \\
\text { (UNIFOA-RJ). }\end{array}$ \\
\hline $2010 / 11$ & ENESSO Vermelha! & $\begin{array}{l}\text { Mario Pereira (Unicastelo), Paola Piomato (PUC-RS), Achilles Lollo } \\
\text { (UFRJ), Nilmar Santos (UERN), Luiza Arcoci (PUC-SP), Eluana Silva } \\
\text { (EMESCAM), Cintia (UEL), Kim Taiuara (UFPE), Lucas Araújo (UFBA) } \\
\text { e Davi Perez (UFSC). }\end{array}$ \\
\hline $2011 / 12$ & $\begin{array}{l}\text { PÉS NO CHÃO: 'A } \\
\text { cabeça pensa onde os } \\
\text { pés pisam' }\end{array}$ & $\begin{array}{l}\text { Larissa Santos (UFS), Carolina Martins (PUC/MG), Josuel Rodrigues } \\
\text { (CEUNSP), Wanderson (UFRJ), Rayara Fernandes (UFES), Thalita } \\
\text { Miranda (UNIFESP) e Cheila Roche (UFPR). }\end{array}$ \\
\hline $2012 / 13$ & Nenhum passo atrás! & $\begin{array}{l}\text { Éverton Santana (Estáciol Recife), Giovanny Simon (UFSC), } \\
\text { Jodeylson Islony (FAR), Pâmela Lins (CEUNIH), William Souza (PUC- } \\
\text { SP), Felipe Souza (UFOP), Juliane Pasqualeto (UFRGS) e Suellen } \\
\text { Santos (UCS). }\end{array}$ \\
\hline $2013 / 14$ & $\begin{array}{l}\text { Façamos nós, por } \\
\text { nossas mãos }\end{array}$ & $\begin{array}{l}\text { Andreia Jordânia (UFPI), Anna Clara (UFPE), Bruna Veiga (UFSC), } \\
\text { Fabrício Araújo (UFTM), Giovanny Simon (UFSC), Igor Souza (UFPI), }\end{array}$ \\
\hline
\end{tabular}

Temporalis, Brasília (DF), ano 19, n. 38, p. 37-51, jul./dez. 2019. | ISSN 2238-1856 


\begin{tabular}{|c|c|c|}
\hline & & $\begin{array}{l}\text { Jéssica Cleophas (UFBA), Laís Gonçalves (UFBA), Marcos Vinicius } \\
\text { (PUC-GO) e Suellen Santos (UCS). }\end{array}$ \\
\hline $2014 / 15$ & $\begin{array}{l}\text { A nossa voz não é } \\
\text { apenas nossa }\end{array}$ & $\begin{array}{l}\text { Mylena Santana (UFPA), Silvania Rabelo (UFMA), Daniele Santos } \\
\text { (UFBA), Jéssica Cleophas (UFBA), Renata Fonseca (UNB), João Paulo } \\
\text { Valdo (UFES), Letícia Rodrigues (UFMT), Tatiana Jardim (UNIRIO), } \\
\text { Bruna Peixer (UFSC), Dandara Manoela (UFSC), Beatriz Oliveira } \\
\text { (PUC-SP) e Cléverson Oliveira (FAMA) }\end{array}$ \\
\hline $2015 / 16$ & $\begin{array}{l}\text { É Tempo de } \\
\text { Dissidência, é Tempo } \\
\text { de Revolução! }\end{array}$ & $\begin{array}{l}\text { Raline Santana (UFPE), Kaic Ribeiro (UNB), Ketinho Oliveira } \\
\text { (UNIFESP), Maria Angélica (UFMA), Terésio de Freitas (PUC/PR), } \\
\text { Adria Lourena (UFPR), Clara Rodrigues, Wallace Terra (UFF/NITERÓI) } \\
\text { e Gilma Vieira (UNB). }\end{array}$ \\
\hline $2016 / 17$ & $\begin{array}{l}\text { Quebrando pedras. } \\
\text { Construindo } \\
\text { resistência }\end{array}$ & $\begin{array}{l}\text { Karoline Santos (UNICAP), Amanda Lima (FAMETRO), Clara } \\
\text { Rodrigues (UFPA), Caio Rodrigues (UNB), Carmel Capitani (UFSC), } \\
\text { Fernanda Gomes (PUC/SP), Maiara Pedral (UFBA), Iohana Moreira } \\
\text { (UFMT) e Mariana Alves (UFAL). }\end{array}$ \\
\hline $2017 / 18$ & $\begin{array}{l}\text { NÃO HOUVE } \\
\text { COORDENAÇÃO } \\
\text { NACIONAL }\end{array}$ & $* * * * * * * * * * * *$ \\
\hline $2018 / 19$ & $\begin{array}{l}\text { Quando resistir faz } \\
\text { parte da estrada, é } \\
\text { tudo ou nada! }\end{array}$ & $\begin{array}{l}\text { Leticia Pereira (UNISINOS), Cleiton Ventura (UNIRIO), Brenda Soares } \\
\text { (UFMT), Laís Silva (UNESP), Willy Cardoso (UFT), Andreza Cândida } \\
\text { (UFG), Sara Ribeiro (UFG), Wellington Monteiro (UFPA), Maysa } \\
\text { Resende (UFTM). }\end{array}$ \\
\hline
\end{tabular}

Fonte: Quadro de coordenações da SESSUNE/ENESSO ${ }^{4}$.

Para contribuir com a organização e representação do MESS, a ENESSO se divide em 7 (sete) regiões ${ }^{5}$ estrategicamente pensadas para melhor realização e fortalecimento da entidade. Sendo assim, cada região tem sua Coordenação Regional (CR) eleita anualmente no Encontro Regional de Estudantes de Serviço Social (ERESS), tendo como tarefa aproximar a militância correspondente com as discussões locais, regionais e nacionais, se configurando em um importante espaço de fortalecimento da base do movimento.

O MESS, através da ENESSO, “[...] articula-se com a categoria e suas entidades representativas na discussão a respeito dos caminhos dotados e desafios postos a formação profissional" (RODRIGUES, 2008, p. 69). Com isso, as/os estudantes conquistou ao longo da sua trajetória, o espaço de representação na ABEPSS. Há, portanto, representação discente na diretoria regional e nacional, estreitando as relações políticas existentes entre as suas entidades.

As/os discentes, com representação na ABEPSS são estudantes de Serviço Social, militantes da ENESSO, que desenvolvem o papel político de articulação entre as duas entidades (ABEPSS e ENESSO), principalmente, a fim de contribuir para o eixo de formação profissional, fortalecendo politicamente o atual Projeto Ético-PolíticoProfissional. Porém, não se limita apenas a isso, esse diálogo e participação nas entidades, significa pra Guimarães (2011), “[...] uma intervenção qualitativa que o MESS pode

\footnotetext{
${ }^{4}$ No quadro mostra dados referentes as gestões de 1988/89 a 2014/15, o anos seguintes foi atualizado pela autora.

${ }^{5}$ Região I - Acre, Amapá, Amazonas, Roraima, Rondônia, Pará, Maranhão e Piauí; Região II - Ceará, Rio Grande do Norte, Paraíba e Pernambuco; Região III - Alagoas, Sergipe e Bahia; Região IV - Tocantins, Goiás, Distrito Federal, Mato Grosso, Mato Grosso do Sul; Região V -Espirito Santo, Minas Gerais e Rio de Janeiro; Região VI - Paraná, Santa Catarina e Rio Grande do Sul e Região VII - São Paulo (EXECUTIVA NACIONAL DE ESTUDANTES DE SERVIÇO SOCIAL, 2013).
}

Temporalis, Brasília (DF), ano 19, n. 38, p. 189-205, jul./dez. 2019. | ISSN 2238-1856 
desenvolver nesse campo, contribuindo para o atendimento das finalidades da ABEPSS, com base nas demandas estudantis" (GUIMARÃES, 2011, p. 46).

Nesses 40 anos, o MESS vem sendo construído por muitas mãos, em diversas gerações. Foi, ainda, permeado de variados grupos políticos, por múltiplas leituras da realidade e por inúmeros desafios. Esses sujeitos, em sua diversidade construíram coletivamente o direcionamento político da Executiva num terreno fecundo de criticidade e de enfrentamento aos ditames do grande capital. Nessa direção a ENESSO tem protagonizado diversas lutas no âmbito da categoria profissional, além da participação e contribuição em momentos históricos do Serviço Social brasileiro como, a exemplo, as elaborações do Código de Ética profissional de 1993 e as Diretrizes Curriculares da ABEPSS de 1996.

\section{UMA ANÁLISE CONTEMPORÂNEA DA REGIÃO II DA ENESSO}

Durante esta pesquisa, observamos que vários desafios são recorrentes e constantes ao longo dos anos, principalmente a partir do advento dos ideais neoliberais, dos quais, destacamos: o acirramento da mercantilização do ensino, a formação política das/os estudantes, as mobilizações para a luta, a transitoriedade das/os militantes, a política financeira do movimento, a relação com os partidos políticos, entre outros.

Evidentemente, é importante pontuarmos aqui, que embora constantes e recorrentes nenhum desafio imposto ao MESS/ENESSO, não pode ser compreendido de forma isolada do seu tempo histórico, do contexto de crise e do rearranjo global do capitalismo. Caso contrário, estaríamos diante de uma análise vazia, acrítica e ahistórica.

Diante do exposto, tomamos para nós a tarefa de problematizar aquilo que identificamos como os atuais desafios da organização política do MESS/ENESSO. Com este texto, não temos nenhuma presunção de contemplar todo o debate ou ainda de esgotar a problematização dos desafios e percalços que se materializam para estes sujeitos, principalmente por consideramos que o "objeto" pesquisado, é multifacetado, dinâmico e jamais se esgotaria numa análise espacial e temporal.

A Região II (R2) da ENESSO, composta pelos estados do Ceará, Rio Grande do Norte, Paraíba e Pernambuco - foco da nossa análise -, tem uma relevância histórica e política na construção e no fortalecimento do MESS nacionalmente. Conforme Ramos (1996) e Guimarães (2011), durante anos, a R2 foi compreendida como a região mais bem articulada, a nível nacional, tendo o maior número de participações nas gestões da Coordenação Nacional, sendo 11 gestões, das quais, 7 foi região sede ${ }^{6}$. Sendo considerada ainda, uma das regiões com maior expressividade estudantil nos seus encontros regionais.

QUADRO 02 - PARTICIPAÇÃO EM GESTÕES DA COORDENAÇÃO NACIONAL

\begin{tabular}{|l|c|c|c|c|c|c|c|}
\hline Região & I & II & III & IV & V & VI & VII \\
\hline Total & 7 & 11 & 8 & 5 & 10 & 7 & 7 \\
\hline
\end{tabular}

Fonte: Pesquisa documental realizada pela autora.

\footnotetext{
${ }^{6}$ Durante os anos de 1988 a 2009 a Coordenação Nacional era composta exclusivamente por uma única região, sendo está a região sede (ENESSO, 2014). É somente com a revisão estatutária de 2010, que a composição da CN sofrerá alterações, devendo ser composta por no mínimo $50 \%$ das regiões, não havendo região sede (EXECUTIVA NACIONAL DE ESTUDANTES DE SERVIÇO SOCIAL, 2013).
}

Temporalis, Brasília (DF), ano 19, n. 38, p. 37-51, jul./dez. 2019. | ISSN 2238-1856 
Segundo Vasconcelos (2003), essas diferenças políticas entre as regiões, resultavam no fortalecimento/crescimento de algumas regiões e o não crescimento de outras, possibilitando assim, a algumas regiões, o poder de uma maior contribuição e um maior peso organizativo, ao conjunto nacional do movimento. Seguindo esse viés, compreendemos que os desafios atuais da Região II, impactam em alguma medida na conjuntura atual da ENESSO nacionalmente e não é algo específico apenas da região.

A transitoriedade das/os militantes do MESS é uma característica estruturante do movimento e indispensável de reflexão, já que implica numa consequência fundamental: as/os estudantes terminam sua militância no momento em que concluem a graduação e deixam o lócus de atuação. Assim, é imprescindível que exista a aproximação de novos sujeitos, para que haja a renovação de quadros e a manutenção do MESS (OLIVEIRA; RIBEIRO; SILVA, 2012).

É nesse contexto de renovação de quadros, que é possível observar uma mudança na dinâmica político-organizativa da Região II. Foi no XXXIII ERESS, realizado em Mossoró (RN), em 2010, que ocorreu a primeira crise política-organizativa expressiva na região. Decorrente de uma ausência de articulação política necessária para compor o quadro da Coordenação Regional, a região não conseguiu eleger uma nova gestão para Coordenação Regional (GUIMARÃES, 2011); o que dificultou, significativamente, na dinâmica da organização do MESS na região durante esse período.

Nos anos que se seguiram, em um esforço coletivo e de unidade, foram criadas uma série de estratégias e ações coletivas de mobilizações para que a Região II retomasse sua articulação política. É nesse período ainda, que começa uma maior aproximação da Executiva com as/os estudantes das Instituições de Ensino Superior (IES) privadas, o que possibilita posteriormente, uma participação considerável destes estudantes no MESS.

Em junho de 2013, o Brasil vivenciou um levante social, que segundo Antunes (2018), só teve idêntico, a campanha pela eleições diretas, em $1985^{7}$ e o Movimento Caras Pintadas, em $1992^{8}$. As revoltas e rebeliões, que se iniciaram em junho de 2013 e que seguiram pelos meses posteriores, tiveram em sua origem causas variadas. Contudo, é na luta contra o aumento das tarifas dos transportes públicos, convocada pelo Movimento Passe Livre (MPL), que se iniciam as primeiras mobilizações.

\footnotetext{
7 Também conhecido como movimento pelas Diretas Já, foi um movimento "[...] histórico de grande relevância para a política do Brasil contemporâneo, de abertura política, de participação e mobilização popular, e de construção de um 'sentimento nacional' que girava em torno das eleições diretas e da votação da Emenda Dante de Oliveira. [...] Foram realizados diversos comícios pelo Brasil, tendo o comício da praça da Sé reunido 1.500 .000 pessoas e se tornado a maior manifestação pública então já realizada no Brasil. A participação de políticos e de artistas reforçavam naquele momento o sentimento de mudança, mesmo com o governo de João Baptista Figueiredo tentando ignorar a notória dimensão do movimento" (BRAGANZA, 2013, p. 2).

${ }^{8}$ Considerado o último manifesto de forma massiva realizado pela juventude brasileira nos anos 1990. 0 movimento dos caras pintada era composto, em sua maioria, por jovens que pediam o impeachment do então presidente Fernando Collor de Mello, envolvido em grandes esquemas de corrupções. O nome do movimento é referente a utilização da tinta guache nas cores verde e amarela usada nos rostos em sinal de patriotismo e expressão.
}

Temporalis, Brasília (DF), ano 19, n. 38, p. 189-205, jul./dez. 2019. | ISSN 2238-1856 
Aos poucos essas mobilizações foram se adensando, de 1 mil para 10 mil e depois para mais 100 mil pessoas. Na medida em que o movimento crescia, ele aumentava também o seu escopo com os outros setores da juventude estudantil, especialmente aquela que não possuía experiência política, mas que estava descontente com sua universidade privada, cara e de péssima qualidade, e que trabalhava para pagar o transporte coletivo, para manter um convênio médico privado ruim etc. (ANTUNES, 2018, p. 250).

Essa conjuntura, possibilitou ao MESS/ENESSO, particularmente a Região II, a expansão de suas bases, através da consolidação de novos Centros Acadêmicos de Serviço Social, principalmente nas IES privadas. Em 2015, existiam 54 IES presenciais com o curso de Serviço Social na Região II (E-MEC, 2015). Deste total, 26 possuíam Centro Acadêmico de Serviço Social (CASS) consolidados e ativos, sendo 9 no Ceará, 6 no Rio Grande do Norte, 4 na Paraíba e 7 no Pernambuco (EXECUTIVA NACIONAL DE ESTUDANTES DE SERVIÇO SOCIAL, 2015).

Contudo, a partir de 2015, de acordo com lamamoto (2017) e Abramides (2017), a conjuntura política, econômica e social do país sofrerá dinamicamente significativas mudanças. Entrará em curso, um golpe parlamentar de direita, orquestrado pelas elites econômicos-politicas brasileira, com apoio da grande mídia e do judiciário, consubstanciado no impeachment da presidenta eleita Dilma Rousseff engendrando as bases do governo ilegítimo de Michel Temer, que sucedeu a referida presidenta após este processo, sendo um governo que ampliou as medidas de ataques as/os trabalhadoras/es e à juventude, em uma ortodoxia neoliberal e de direita.

A múltiplas alterações, decorrente dessa nova conjuntura, provocaram no MESS/ENESSO - bem como nas demais organizações políticas de esquerda -, um grande giro na sua dinâmica político-organizativa. O que provocou grandes impactos, indicando inúmeras dificuldades no processo de organização e mobilização das/os militantes, que precisam ser compreendidos para que possamos avançar no campo teórico da organização política.

Diante deste novo cenário, parte significante das organizações políticas, entre eles, os partidos políticos de esquerda e os movimentos sociais, que disputavam e formulavam o MESS na Região II, avaliaram que, naquele momento, a Executiva não era um espaço importante de disputa e de desprendimento de forças, deixando assim, de priorizar a sua aproximação com o movimento.

Para compreendermos o que isso representa, é importante pontuarmos, que historicamente, é possível observar a presença de partidos políticos no Movimento Estudantil. Uma vez que, as diversas correntes partidárias priorizavam a aproximação com os Movimentos Sociais - principalmente o ME e o Movimento Sindical -, entendendo que esses movimentos se constituíram como espaços estratégicos, haja vista a capacidade que possuem para organizar respectivamente a juventude e a classe trabalhadora. Com essa articulação, é possível observar que muitos militantes do ME são, também, militantes partidários, o que faz com que se estabeleça uma relação dinâmica e, em alguns momentos, também tensa (GUIMARÃES, 2011).

Nesse viés, Rodrigues (2008) compreende que as/os estudantes organizadas/os politicamente em partidos políticos e/ou organizações populares acabam se diferenciando entre as/os demais militantes por contribuírem no desenvolvimento de

Temporalis, Brasília (DF), ano 19, n. 38, p. 37-51, jul./dez. 2019. | ISSN 2238-1856 
ações mais qualificadas, o que por sua vez, acabam exercendo o papel de protagonista na proposição, articulação e implementação das estratégias de ações defendidas pelo ME. No que se refere aos espaços do MESS, diversas/os autoras/es, entre essas/es: Ramos (1996), Rodrigues (2008) e Guimarães (2011) sinalizavam para a importância e a necessidade de articulação entre os partidos políticos e organizações populares no MESS, numa perspectiva a considerar o vasto leque de contribuições que esses grupos podem dar para a construção de linhas políticas de atuação e, principalmente para formação política das/os militantes no movimento, possibilitando a complementação a fragilidade de formação teórico-política no âmbito do MESS.

As divergências e as disputas promoveram, ao longo dos anos, tensões na organização política das/os estudantes de Serviço Social. Advindas, principalmente, dos diferentes posicionamentos entre as diversas correntes partidárias e/ou do tensionamento entre as/os militantes organizadas/os partidariamente e as/os militantes independentes ${ }^{9}$, que provocaram uma série de embates, que por vezes, limitaram as discussões, sectarizaram posições e dificultaram o fortalecimento das lutas. Contribuindo assim, para um desgaste político dentro do movimento, e por ora, da saída de alguns grupos políticos do MESS, fragilizando a formação política no interior do movimento.

Se a formação política está fragilizada, segundo Guimarães (2011), "[...] por consequência, as ações perdem a radicalidade e o seu potencial de intervir qualitativamente na realidade, pois um aspecto não está dissociado do outro. Ao contrário, trata-se de uma relação intrínseca e direta" (GUIMARÃES, 2011, p. 72). Quanto mais fragilizada a formação política, mais esvaziado serão os debates e as ações do movimento; demandando as/os militantes uma série de novos desafios no que diz respeito a formação destes espaços.

Obviamente, não se buscou neste estudo, apontar culpados e/ou culpabilizar as disputas e divergências políticas ocorridas no MESS pelo afastamento de alguns grupos políticos do movimento, pois, além de acreditarmos que estaríamos diante de uma análise vazia, entendemos ainda, que essas divergências e disputas construtivas são necessárias e devem ser evidenciadas na proporção em que elas dão movimento e enriquecem o debate. Contudo, entendemos que é preciso enxergar os erros do passado, para não repetirmos no presente e avançarmos no futuro.

Ao longo da pesquisa, foi possível observar ainda, que o agravamento da precarização das universidades, provenientes das medidas neoliberais, efetivadas pelo governo ilegítimo de Temer, principalmente, após a aprovação da Proposta de Emenda Constitucional (PEC) 55, que tem por objetivo congelar as despesas do Governo Federal, por até 20 anos, afetando principal e diretamente as políticas e serviços sociais públicos, o MESS "perdeu" não somente os espaços públicos das universidades para a construção dos eventos, como também, outros incentivos importantes, como os transportes universitários, que levavam os/as estudantes para os eventos, o que dificultou ainda mais, a organização e participação dos espaços do MESS. Para suprir essas ausências, a comissões organizadoras tiveram que encarecer as inscrições, consequente, aumentando

\footnotetext{
9 Nomenclatura atribuída aos estudantes que não aderiram a nenhum dos grupos políticos que atuaram/atuam no ME.
}

Temporalis, Brasília (DF), ano 19, n. 38, p. 189-205, jul./dez. 2019. | ISSN 2238-1856 
mormerros socasus ssencososcant tempordils

o custo na participação das/os estudantes no evento, o que promoveu um esvaziamento destes.

A ausência dos partidos políticos e das organizações populares, - principalmente na Região II da ENESSO -, o agravamento do sucateamento das universidades, o avanço das ideias conservadoras, entre outros fatores, dificultaram ainda mais a organização política das/os estudantes no MESS e aprofundaram significativamente os desafios anteriormente citados.

Os quadros não vem conseguindo ser renovados, apesar dos esforços e das estratégias das/os militantes que ainda restam na região; dos 26 CASS, - acima citados, cerca de 9 permanecem em atividade; a Coordenação Regional (CR) II estar sem gestão há 2 anos consecutivos (2017/18 e 2018/19), sendo a primeira vez na história da ENESSO que uma região fica duas gestões consecutivas sem atuação; o último encontro massivo construído na Região II foi o XL ERESS, realizado no IFCE, Campus Iguatú (CE), em abril de 2017.

Em 2019, houve uma articulação entre as escolas da região, principalmente, as do Ceará e do Rio Grande do Norte, buscando a rearticulação do MESS e a organização do XLI ERESS, que tem data prevista para abril/2019, em Natal/RN. No entanto, as ações são, na maioria das vez, dificultadas pela pouca experiência dos mesmo no movimento - uma vez que se trata de militantes novos -, ou até mesmo, pelos vínculos pessoas, já que a maioria dos militantes de estados diferentes não se conhecem pessoalmente.

Neste sentido, é imprescindível observar que a história da construção do MESS, ao longo dessas quatro décadas deixou um legado, no plano da política, na qual gerações de profissionais se movimentam, reinventando a resistência na crise, arquitetando estratégias que abordam a complexa relação entre a luta da emancipação política e o horizonte da emancipação humana. Assim, é preciso apostar nas contradições que surgem de todo processo determinado pela luta de classes, e utilizar-se da nossa inteligência e aptidão de mobilização para produzir, em conjunto com sujeitos coletivos e individuais, estratégias com potencial de enfrentar esse processo.

\section{CONSIDERAÇÕES FINAIS}

Nesses tempos temerosos e intempestivos, de avanço da extrema direita conservadora, no Brasil e na América Latina, cuja aridez de projetos de futuro, estão nos padrões do grande capital, com ataques direto a democracia e aos direitos sociais, somos chamados a se encorpar de força política, reafirmando a importância da atuação política no Serviço Social e a necessidade do fortalecimento da militância no MESS.

Os desafios são muitos, porém, é urgente e necessário que numa ação coletiva, de articulação conjunta com as entidades da categoria (Conjunto CFESS/CRESS e ABEPSS), pense e se desenvolva estratégias de aproximação e manutenção desse movimento, uma vez que o MESS, na figura da ENESSO, é a porta de entrada para a organização política da categoria. 
É esse movimento que permite as/os estudantes se encantem pela vivência, ações e debates políticos. Fortalecendo mentes e corações revolucionários, que ao serem conquistados, se (re)encantem, se (re)criem, se (re)inventem; possibilitando a luta em defesa do projeto profissional e do ensino de qualidade e na crítica a sociabilidade burguesa. Ousamos dizer, que se no processo de formação profissional de qualidade é necessário a articulação do tripé ensino-pesquisa-extensão, o Movimento Estudantil entra como um quarto elemento essencial e substancial nesse processo, que é a dimensão política.

Por isso, é preciso unir forças para construir espaços organizados e movimentos estudantis, justamente para fortalecer a proposta de ensino defendido pela ABEPSS e lutar pelo direito a uma educação pública, laica, universal e de qualidade. A luta apenas começou.

\section{REFERÊNCIAS}

ABRAMIDES, Maria Beatriz Costa. Lutas sociais e desafios da classe trabalhadora: reafirmar o projeto profissional do Serviço Social brasileiro. Serviço Social e Sociedade, São Paulo: Cortez, n. 129, p. 366-386, 2017.

ANTUNES, Ricardo. O privilégio da servidão: o novo proletariado de serviços na era digital. ed. São Paulo: Boitempo, 2018.

BRAGANZA, Rochelle Guttierrez. As “diretas já": uma análise sobre o impacto da campanha no processo de transição política brasileira. Natal, 2013. Disponível em: http://www.snh2013.anpuh.org/resources/anais/27/1364952315_ARQUIVO_ARTIGOANPUH _1_.pdf. Acesso em: $1^{\circ}$ jun. 2018.

BEHRING, Elaine Rossetti; BOSCHETTI, Ivanete. Politica Social: fundamentos e história. 9. ed. São Paulo: Cortez, 2011.

EXECUTIVA NACIONAL DE ESTUDANTES DE SERVIÇO SOCIAL. Mapeamento das IES presenciais da ENESSO - Região II: Gestão 2014/2015 “A luta é direito de fazer um mundo novo". [s. I.], 2015.

EXECUTIVA NACIONAL DE ESTUDANTES DE SERVIÇO SOCIAL. Quadros de Coordenações Nacionais e Regionais da SESSUNE/ENESSO. [s. I.], 2014. Disponível em: https://enessooficial.files.wordpress.com/2011/06/quadro-de-coordenac3a7c3b5es-daenesso.pdf. Acesso em: $1^{\circ}$ jun. 2018.

EXECUTIVA NACIONAL DE ESTUDANTES DE SERVIÇO SOCIAL. Estatuto da ENESSO. Cuiabá, 2013.

EXECUTIVA NACIONAL DE ESTUDANTES DE SERVIÇO SOCIAL. Pro dia nascer feliz: contribuição para Movimento Estudantil de Serviço Social. Salvador, 1994.

GUIMARÃES, Maria Clariça Ribeiro. Nosso sonho não faz silêncio: os desafios do Movimento Estudantil de Serviço Social. Monografia. Mossoró: UERN, 2011. 
IAMAMOTO, Marilda Villela. 80 anos do Serviço Social brasileiro: a certeza na frente e a história na mão. Serviço Social e Sociedade, São Paulo: Cortez, n. 128. p. 13-38, jan./abr. 2017.

MOREIRA, Tales Willyan Fornazier. Movimento Estudantil de Serviço Social e o Projeto Ético-Político na formação profissional. Monografia. Uberaba: UFTM, 2016.

OLIVEIRA, Renata Priscila; RIBEIRO, Ana Camila; SILVA, Samuel Germano Moreira. A transitoriedade do movimento estudantil e o trabalho de base: desafios para o enraizamento da ENESSO nas Unidades de Formações Acadêmicas Privadas. Campina Grande, 2012.

OLIVEIRA, Inaê Soares. A contribuição do Movimento Estudantil na formação política e cultural dos/as estudantes de Serviço Social. Monografia. Fortaleza: UECE, 2014.

RAMOS, Sâmya Rodrigues. A ação política do Movimento Estudantil de Serviço Social: caminhos, histórico e alianças com outros sujeitos coletivos. Recife: UFPE, 1996.

RODRIGUES, Larissa de Oliveira. O Movimento Estudantil e a formação política do(a) estudante de Serviço Social: contribuições e desafios. Monografia. Natal: UFRN, 2008.

SANTOS, Tiago Barbosa. A participação política dos estudantes de Serviço Social na defesa e consolidação da direção social da formação: a práxis política dos estudantes e a relação profissional. Monografia. São Paulo: PUC, 2007.

SILVA, Andrea Alice Rodrigues. Convite a rebeldia: uma reflexão sobre o Movimento Estudantil de Serviço Social e seus desafios na contemporaneidade. Monografia.

Fortaleza: UECE, 2008.

SIMIONATTO, Ivete. A expressões ideoculturais da crise capitalista na atualidade e sua influência teórico-política. Brasília (DF): CFESS; ABEPSS, 2009.

VASCONCELOS, Ailton Marques. A trajetória política da organização dos estudantes de Serviço Social: 1978-2002 e a sua relação com o projeto de formação profissional. Monografia. São Paulo: PUC, 2003. 